Malone, K. M., H. H. Jones, A. M. Betancourt, T. M. Terhune II, and K. E. Sieving. 2019. Video documentation of predators and nest defense at Bachman's Sparrow nests. Avian Conservation and Ecology 14(2):6. https://doi.org/10.5751/ACE-01409-140206

Copyright (C) 2019 by the author(s). Published here under license by the Resilience Alliance.

\title{
Video documentation of predators and nest defense at Bachman's Sparrow nests
}

\author{
Kristen M. Malone ${ }^{1,2}$, Harrison H. Jones ${ }^{3}$, Adriana M. Betancourt ${ }^{1}$, Theron M. Terhune II ${ }^{2}$ and Kathryn E. Sieving ${ }^{1}$ \\ ${ }^{1}$ University of Florida, Department of Wildlife Ecology and Conservation, ${ }^{2}$ Tall Timbers, ${ }^{3}$ University of Florida, Department of \\ Biology
}

\begin{abstract}
Bachman's Sparrow (Peucaea aestivalis) is a species of conservation concern throughout its range and an effective indicator of healthy pine savanna ecosystems in the southeastern United States. Their secretive nesting behavior means that many aspects of their nesting ecology, including specific knowledge of the nest predator community and nest defense behaviors are insufficiently described. This information is an important first step in determining the link between management practices and reproductive success. We monitored 86 Bachman's Sparrow nests, 65 with constant video surveillance, to describe the nest predator community, cause-specific nest mortality rate, and nest defense behavior. We identified 12 predator species from 37 predation events. Snakes were the dominant predator type, responsible for $51 \%$ of identified predation events, followed by mesomammals (19\%), small mammals (16\%), and others (14\%). Nest defense behavior included ptiloerection and chasing but was rare (16\% of predation events) and effective $67 \%$ of the time. Daily nest survival was 0.936 (CI: $0.894-0.967)$ and neither season, year, nor site explained a significant amount of variation in estimates of cause-specific daily nest mortality. Raccoons were not detected at Bachman's Sparrow nests despite being one of the most common nest predators in other avian nest surveillance studies. Future studies should explore the link between prescribed fire, nest predation, and snake abundance or activity in southeastern pine savanna.
\end{abstract}

\section{Documentation vidéo de prédateurs et de comportements de défense aux nids chez le Bruant des pinèdes}

RÉSUMÉ. Le Bruant des pinèdes (Peucaea aestivalis) est une espèce préoccupante dans l'ensemble de son aire et est un bon indicateur d'écosystèmes de pinèdes sains dans le sud-est des États-Unis. Leur comportement discret au nid explique que de nombreux aspects de leur écologie de nidification soient encore mal décrits. Cette connaissance est une première étape importante si l'on veut établir les liens entre les pratiques de gestion et le succès de reproduction. Nous avons surveillé 86 nids de Bruant des pinèdes, dont 65 sous vidéo continue, afin de décrire la communauté de prédateurs de nids, le taux de mortalité au nid spécifique aux causes et les comportements de défense au nid. Nous avons identifié 12 espèces de prédateurs à partir de 37 cas de prédation. Les serpents étaient les principaux prédateurs, responsables de $51 \%$ des cas de prédation identifiés, suivis des mésomammifères (19\%), des petits mammifères (16\%) et d'autres prédateurs (14\%). Les comportements de défense au nid comprenaient la ptiloérection et la poursuite, mais ils survenaient rarement ( $16 \%$ des cas de prédation) et étaient efficaces $67 \%$ du temps. La survie quotidienne au nid était de 0,936 (CI: 0,894 - 0,967), et ni la saison, l'année ou le site n'ont expliqué l'importante variation des estimations de mortalité quotidienne au nid spécifique aux causes. Les ratons laveurs n'ont pas été détectés aux nids de bruants, bien qu'ils se soient avéré un des prédateurs les plus communs dans d'autres études de surveillance de nids. Les recherches futures devraient explorer le lien entre le brûlage dirigé, la prédation des nids et l'abondance ou l'activité des serpents dans les pinèdes du sud-est.

Key Words: black racer; cause-specific nest mortality; corn snake; mesomammals; Peucaea aestivalis; prescribed fire; video surveillance

\section{INTRODUCTION}

Grassland birds have undergone extensive population declines over the past 50 years and remain one of the most at-risk guilds of birds in North America (Brennan and Kuvlesky 2005, NABCI 2017). Nests of grassland birds are depredated by a diverse assemblage of snakes, rodents, mesomammals, corvids, and birds of prey (DeGregorio et al. 2016) that differ in the sensory cues used for locating nests (Colombelli-Négrel and Kleindorfer 2009) and affect different patterns of nest predation (Andren 1992, DeGregorio et al. 2014). Grassland bird nest predation is influenced by the degree of habitat fragmentation (Nour et al. 1993, Hannon and Cotterill 1998), specific nest-site characteristics (Schmidt 1999), and management regimes including prescribed fire (Lyons et al. 2015). Moreover, altered nest predator communities in systems where top predators have been removed (Sovada et al. 1995), or where disturbance allows for pervasion of predators from other habitats (Dijak and Thompson 2000, Renfrew and Ribic 2003), may impact the nest success and population dynamics of grassland birds. Identifying nest predators is a first step in predicting management outcomes that alter habitat for predator or prey (Ellison et al. 2013, Lyons et al. 2015).

Many grassland bird species demonstrate nest defense behavior in the presence of predators (Ellison and Ribic 2012), but behaviors vary in relation to the perceived risk posed by the 
predator (Curio et al. 1983), and by predator species (Kleindorfer et al. 2005). The costs and benefits of nest defense behavior may diminish with some predator types, e.g., snakes (Ellison and Ribic 2012, Ellis-Felege et al. 2013), and/or for larger predators (Vickery et al. 1992). Nest defense behavior can have significant outcomes on nest success against some predator species; for instance, the success of Wood Thrush (Hylocichla mustelina) nest defense and overall nest success was significantly different against different dominant nest predators (Schmidt and Whelan 2005). Identifying defense behaviors at the nest, and the context in which they are used, can help determine how the predator community is likely to influence nest predation rates.

Bachman's Sparrow (Peucaea aestivalis) is a species of conservation concern endemic to pine savannas of the southeastern United States. The species has been declining throughout its range over the past five decades (Sauer et al. 2017). Most of the remaining Bachman's Sparrow habitat in the Red Hills region (Fig. 1) and many other locales throughout the southeast consists of open pine savanna on private lands that are often intensively managed for the Northern Bobwhite (Colinus virginianus). Bachman's Sparrow is a habitat specialist that is sensitive to changes in landscape composition (Taillie et al. 2015), habitat fragmentation (Jones et al. 2017, Winiarski et al. 2017a), and ground cover vegetation, as influenced by fire regime (Cox and Jones 2009, Jones et al. 2013). The dependency of Bachman's Sparrow on habitat maintained by frequent fire has been welldocumented (Tucker et al. 2004, Cox and Jones 2007, 2009, Jones et al. 2013) and makes this species an effective indicator of healthy pine savanna ecosystems (Taillie et al. 2015). Except for singing males during the breeding season, the species is especially cryptic and females are rarely detected. Their cryptic domed-cup ground nests and secretive behavior around the nest (Haggerty 1988, 1995), makes nests difficult to find and study.

Fig. 1. The study took place in the Red Hills region of northern Florida and southern Georgia (inset) on two properties (yellow) managed for open pine savannah that were surrounded by other properties with similar management (green).

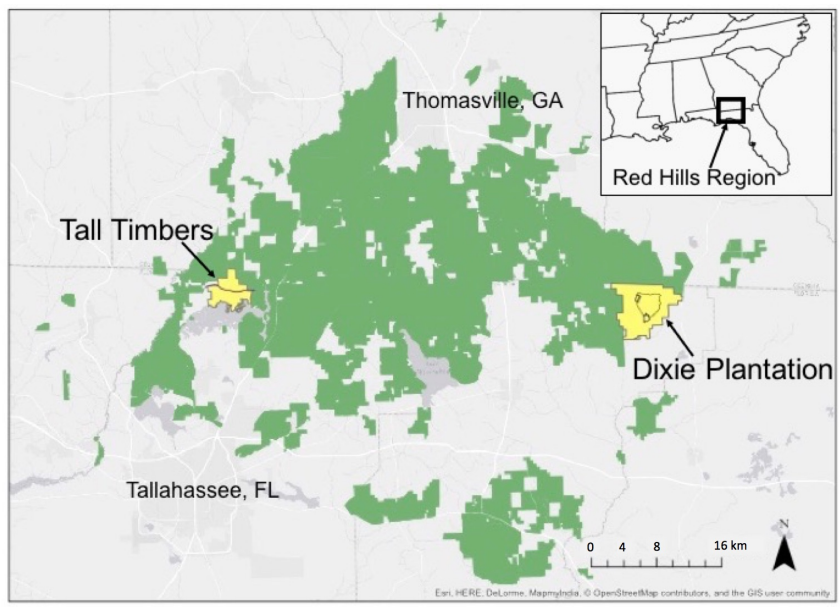

Many aspects of Bachman's Sparrow ecology, therefore, need additional study (Dunning et al. 2018), including specific knowledge of the nest predator community, nest defense behaviors, and reproductive success. This information is an important first step in determining the link between management practices and reproductive success (Lyons et al. 2015). We therefore monitored Bachman's Sparrow nests using video surveillance on restored pine savanna in the Red Hills region of northern Florida to describe the following: (1) the nest predator community of Bachman's Sparrow along with (2) cause-specific nest mortality and proportional risk germane to different predator types in our system, and (3) the nest defense behavior exhibited by this species.

\section{METHODS}

\section{Study site}

The study took place on two properties owned and managed by Tall Timbers, located in northern Florida in the Red Hills region (Fig. 1). The Red Hills physiographic region is approximately 405,000 ha and was historically dominated by longleaf pine (Pinus palustris) and shortleaf pine (Pinus echinata) savanna. Private hunting plantations managed for Northern Bobwhite dominate the region (Fig. 1) and maintain habitat for many pine savanna species. One site was the core management area ( 800 ha) at Dixie Plantation (Dixie hereafter; 3682 ha) located in Jefferson County, Florida. The second site, Tall Timbers (TT hereafter; 1300 ha), was in Leon County, Florida. Both sites were classified as oldfield, historical agricultural land. Uplands were pine savanna dominated by loblolly pine (Pinus taeda) and shortleaf pine, and included longleaf pine as well as a variety of oak species. Management activities included burning approximately half of each property in March-April (1-2-yr fire return interval), rollerchopping (mechanical shrub reduction), and mowing in the fall, and supplemental feeding for Northern Bobwhite every few weeks throughout the year. Mesomammalian predators were trapped and removed from approximately May-September to relieve predation pressure on Northern Bobwhite nests; however, their activity was reduced, not eliminated (Jackson et al. 2018, Palmer et al. 2019).

\section{Nest searching and video surveillance}

From mid-April to late August during each year of the study we nest-searched on eight 15 -ha plots randomly placed throughout both properties (16 total). We found nests using behavioral cues given by parents and systematic searches by walking through nesting microhabitat to flush an attending parent. Nesting adults exhibit cryptic behavior but can be seen taking invertebrate food to the nest. We flagged nests with two small, pink flags tied close to the ground, each $2.5 \mathrm{~m}$ from the nest. A human observer checked nests every 1-5 d regardless of whether the nest was video monitored. We took caution not to disturb vegetation surrounding nests, especially not in a path leading to the nest, and to minimize time spent at or near the nest.

We used video surveillance to monitor the fate of a subset of nests. Our surveillance systems generally followed the recommendations of Cox et al. (2012). Cameras were small $(10 \mathrm{~cm}$ long by $6 \mathrm{~cm}$ in diameter), camouflaged, placed $2-10 \mathrm{~cm}$ above the ground, at a minimum of $30 \mathrm{~cm}$ from the nest, and at an angle to the nest entrance. We used one of two weatherproof, day/night, 3.6-mm lens cameras (ZOSI CCTV ZG2116E or Rainbow NTSC BC70WIRC) and a 15-m cord to connect the camera to a digital 
video recorder (DVR) and a $12-\mathrm{V}$ battery. The cord was covered in black, 2.5-cm Techflex (Techflex, Inc. Sparta, NJ) to prevent damage from chewing rodents. We disguised and partially covered the camera and cord using vegetation collected from the site (pine needles, dead leaves, sticks, etc.). We covered in camouflaged tape the first 1-2 $\mathrm{m}$ of the cord closest to the nest. The cameras used infrared light, which is discrete in the dark and likely not detectable by most predators (Sanders and Maloney 2002).

To ensure that video surveillance was not negatively affecting nest survival, after the first two seasons, we analyzed its effect on daily nest survival. We used a Bayesian analysis of the daily nest survival model presented by Royle and Dorazio (2008) with the binary surveillance variable as the only covariate. We included the 51 nests that were found in the first two seasons and included nests with $(N=37)$ and without $(N=14)$ video surveillance. We built and analyzed the model using JAGS implemented in R (version 3.3.1, R Development Core Team 2016) with the jagsUI package (Plummer 2013), which uses Markov Chain Monte Carlo (MCMC) simulation to estimate parameters based on posterior distributions. We initiated three simulation chains to estimate the posterior distribution based on 80,000 iterations and a burn-in of 40,000. We assessed convergence with $\mathrm{R}$-hat values and visual inspection of traceplots (Brooks and Roberts 1998). We did not find a significant effect of nest surveillance on daily nest survival $(=0.986 ; 95 \%$ credible interval $[\mathrm{CI}]=-0.025-1.918$; Betancourt et al. 2017). Thus, for 2017, we used surveillance on 28 of 35 nests.

We reviewed video with the primary objective of identifying predators responsible for nest failure. If a partial depredation was evidenced from nest checks, we also reviewed video to identify the predator responsible for the partial depredation. For these nests, we targeted review to only a portion of the video until the predation event was seen. We reviewed video from a subset of nests $(N=22)$ from the first two seasons in full (not targeted for predation events only) using up to $16 \mathrm{x}$ viewing speed to detect attempted predation events and defense behavior that was successful and not detected using targeted reviewing. Therefore, in our description of the nest predator community, we include predators that were successful in nest depredation and that attempted nest depredation but were thwarted by a defensive parent.

\section{Cause-specific nest mortality analysis}

We used a Bayesian formulation of a logistic-exposure, multinomial nest mortality model to estimate daily survival for all nests, as well as daily probability of mortality from different predator types (Darrah et al. 2018). We chose to present multinomial nest mortality rates because they can be compared across studies to infer larger scale patterns, which is a limitation of presenting only counts. We used Bayesian methods because they are typically less biased than maximum likelihood estimation methods for small sample sizes such as ours (Le Cam 1990, Kéry 2010). We classified fates either as successful (fledged $\geq 1$ chick), failed because of snakes, failed because of mesomammals, failed because of small mammals, or failed because of other predator type. We treated unknown predator identity as missing data, which contributes to uncertainty in the estimates. We did not incorporate partial depredations in this analysis because they did not cause nest failure. Fate was assumed to be categorized correctly and assumed to vary independently among nests.
We included the Julian date the nest was found, year $(2015,2016$, 2017), and property (TT or Dixie) as covariates in the model. The date found serves as a proxy for nest initiation date because nest survival for this species has been shown to decrease over the course of the breeding season (Winiarski et al. 2017b) and because initiation date could not be calculated for nests that were found and failed during the incubation stage. We specified vague priors for all model parameters. Similar to the previous analysis, we built and analyzed the model using JAGS with three simulation chains for 70,000 iterations and a burn-in of 40,000.

\section{RESULTS}

We found 86 nests during $2015(N=25), 2016(N=26)$, and 2017 $(N=35)$. The earliest nest in any season was found on 25 April and the latest was 15 August. The median date was 9 June. We found four nests in the laying stage, 27 in the incubation stage, and 55 in the nestling stage. We found most nests $(65 \% ; 5$ incubation stage, 51 nestling stage) using behavioral cues exhibited by the parents, and the remainder (35\%; 4 laying stage, 22 incubation stage, 4 nestling stage) when a parent was flushed off the nest. We video-monitored 65 nests $(76 \%)$.

We recorded 37 predation events where the predator could be identified at least to predator type (Table 1; 37 is the total we used to calculate all percentages below, unless otherwise noted). We identified 12 species belonging to 3 major predator types: snakes were responsible for $19(51 \%)$ of the predation events, mesomammals for $7(19 \%)$, and small mammals for $6(16 \%)$. We also detected depredations by red-imported fire ants (Solenopsis invicta) and Blue Jays (Cyanocitta cristata), responsible for the remaining five $(14 \%)$ predation events (Table 1$)$. Snake species included southern black racer (Coluber constrictor), corn snake (Pantherophis guttata), eastern coachwhip (Masticophis flagellum), eastern cottonmouth (Agkistridon piscivorous), and gray rat snake (Pantherophis spiloides; Table 1). Mesomammal species included coyote (Canis latrans) and bobcat (Lynx rufus). Small mammal species included hispid cotton rat (Sigmoidon hispidus), cotton mouse (Peromyscus gossypinus), and eastern wood rat (Neotoma floridana). We could not identify predators responsible for 17 depredation events because the nest was not under surveillance or there was an equipment malfunction or other circumstance, i.e., vegetation fallen in front of camera, that prevented identification. Five of the nests were parasitized by Brown-headed Cowbirds (Molothrus ater), although each of these nests was either depredated or fledged $\geq 1$ host chick.

\section{Nest defense behavior}

Parents defended nests on six occasions (16\% of predation events; Table 2). Defense behavior effectively deterred predators $67 \%$ of the time, but only $50 \%$ of these nests were ultimately successful. Parents were at the nest (within the camera view) during $49 \%$ of the predation events and away from the nest (or at least outside of the camera view) for $43 \%$ of the predation events. During $8 \%$ of predation events, we were uncertain if a parent was at the nest. On three of the nest defense occasions, the parent exhibited ptiloerection while just outside the nest. One individual exhibited this behavior toward a black racer and was unsuccessful. Another individual exhibited ptiloerection against what we presumed was a predator but could not identify because it did not come into the camera view; on this occasion, the parent was successful, as the 
Table 1. Identification of predators from video monitoring of Bachman's Sparrow (Peucaea aestivalis) nests at two properties in northern Florida in 2015, 2016, and 2017. Some nests were visited by more than one predator.

\begin{tabular}{|c|c|c|c|c|}
\hline & 2015 & 2016 & 2017 & Total \\
\hline Total nests found & 25 & 26 & 35 & 86 \\
\hline Nests with video surveillance & 13 & 24 & 28 & 65 \\
\hline \multicolumn{5}{|l|}{ Snakes } \\
\hline Black racer (Coluber constrictor) & 0 & 2 & 5 & 7 \\
\hline Corn snake (Pantherophis guttata) & & 1 & 3 & 7 \\
\hline Gray rat snake (Pantherophis spiloides) & 0 & 0 & 1 & 1 \\
\hline Cottonmouth (Agkistrodon piscivorous) & 1 & 0 & 0 & 1 \\
\hline Coachwhip (Masticophis flagellum) & 0 & 0 & 1 & 1 \\
\hline Unknown species & 1 & 0 & 1 & 2 \\
\hline \multicolumn{5}{|l|}{ Mesomammals } \\
\hline Bobcat (Lynx rufus) & 1 & 0 & 2 & 3 \\
\hline Coyote (Canis latrans) & 0 & 2 & 1 & 3 \\
\hline Unknown species & 0 & 0 & 1 & 1 \\
\hline \multicolumn{5}{|l|}{ Small mammals } \\
\hline Cotton rat (Sigmoidon hispidus) & 0 & 2 & 1 & 3 \\
\hline Cotton mouse (Peromyscus gossypinus) & 0 & 0 & 1 & 1 \\
\hline Wood rat (Neotoma floridana) & 1 & 0 & 0 & 1 \\
\hline Unknown species & 1 & 0 & 0 & 1 \\
\hline \multicolumn{5}{|l|}{ Other } \\
\hline Fire ants (Solenopsis invicta) & 0 & 0 & 2 & 2 \\
\hline Blue Jay (Cyanocitta cristata) & 0 & 0 & 3 & 3 \\
\hline Predator not identified & 6 & 2 & 9 & 17 \\
\hline
\end{tabular}

nest was not depredated and ultimately fledged. On a third occasion, the parent exhibited ptiloerection toward a cottonmouth, then flew in the opposite direction of the nest and the cottonmouth followed. The nest was not depredated by the cottonmouth and ultimately fledged. On three occasions, an approaching predator was chased from the nest by the parent. On one of these occasions, the parent successfully defended against a black racer, but the nest was ultimately depredated. Twice, parents at two nests chased an approaching cotton rat, but only one was successful in deterring the predator and ultimately fledged, while the other was partially depredated by the cotton rat and ultimately depredated by a coyote. Both types of defense occurred during incubation and nestling stages.

\section{Cause-specific mortality analysis}

With year, property, and the date the nest was found included in the model, average daily nest survival was 0.936 (95\% CI: 0.894 0.967). This estimate extrapolated over the $25-\mathrm{d}$ nesting cycle yielded the mean nest success rate of $19 \%(6 \%-43 \%)$. The mean cause-specific daily mortality estimate was highest for mortality due to snakes $(0.023,95 \% \mathrm{CI}=0.007-0.053$; Fig. 2). However, credible intervals overlapped among mortality types (Fig. 2). Year and property did not adequately explain variation in mortality type, nor was there an effect of nest discovery date on any mortality type.

\section{DISCUSSION}

We described the Bachman's Sparrow nest predator suite in the Red Hills region, detecting a diverse assemblage dominated by snakes. We also found that parental nest defense behavior was rare, although effective $67 \%$ of the time when employed. In contrast to significant evidence from nest surveillance studies on other bird species (DeGregorio et al. 2016), we did not document predation of any Bachman's Sparrow nest by a raccoon. This was interesting given that raccoons accounted for $23 \%(N=30)$ of depredations on Northern Bobwhite nests with video-surveillance during a concurrent study at the same field sites (KMM, unpublished data). Future studies that examine how habitat management influences Bachman's Sparrow predator populations, particularly snakes, would aid conservation efforts when nest survival rates are low.

Fig. 2. Cause-specific nest mortality estimates for Bachman's Sparrow (Peucaea aestivalis) nests monitored with video surveillance in North Florida in 2015, 2016, and 2017. Points represent mean estimates and lines are $95 \%$ Credible Intervals.

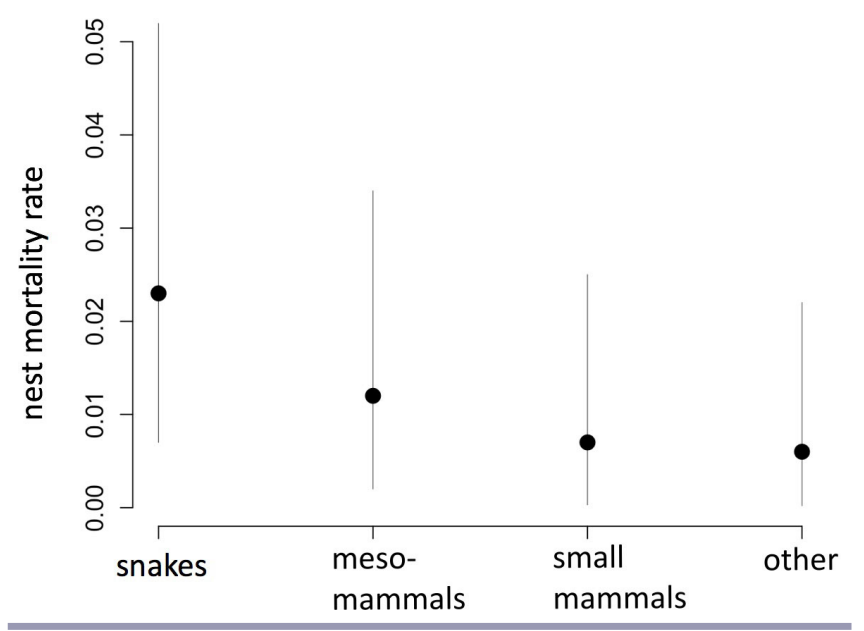


Table 2. Description of Bachman's Sparrow (Peucaea aestivalis) parental defense of nests at two properties in northern Florida in 2015, 2016 and 2017.

\begin{tabular}{|c|c|c|c|c|c|c|}
\hline Predator observed & Date of event & $\begin{array}{c}\text { Time of } \\
\text { event }\end{array}$ & Nest stage & Description of defense & $\begin{array}{c}\text { Result of } \\
\text { defense }\end{array}$ & $\begin{array}{l}\text { Ultimate nest } \\
\text { fate }\end{array}$ \\
\hline $\begin{array}{l}\text { Black racer } \\
\text { (Coluber constrictor) }\end{array}$ & 23 June 2016 & $14: 34$ & incubation & $\begin{array}{l}\text { Snake approaches and parent chases it away } \\
\text { from the nest. }\end{array}$ & successful & failed \\
\hline Black racer & 3 June 2016 & $16: 32$ & incubation & $\begin{array}{l}\text { Snake approaches and parent puffs-up } \\
\text { feathers, which startles predator away from } \\
\text { the nest. }\end{array}$ & failed & failed \\
\hline $\begin{array}{l}\text { Hispid cotton rat } \\
\text { (Sigmoidon hispidus) }\end{array}$ & 6 July 2016 & $0: 22$ & incubation & $\begin{array}{l}\text { Cotton rat approaches and parent attempts } \\
\text { to chase it away from the nest. }\end{array}$ & failed & failed \\
\hline Hispid cotton rat & 30 May 2016 & $20: 22$ & nestling & $\begin{array}{l}\text { Cotton rat approaches and parent chases it } \\
\text { away from the nest. }\end{array}$ & successful & successful \\
\hline Unknown species & 30 June 2016 & 0:06 & nestling & $\begin{array}{l}\text { Predator approaches and parent puffs-up } \\
\text { feathers, predator does not continue } \\
\text { approach. }\end{array}$ & successful & successful \\
\hline $\begin{array}{l}\text { Eastern cottonmouth } \\
\text { (Agkistridon piscivorous) }\end{array}$ & 5 August 2015 & $16: 44$ & nestling & $\begin{array}{l}\text { Snake approaches and parent puffs-up } \\
\text { feathers, flies away from the nest, distracting } \\
\text { the snake from the nest. }\end{array}$ & successful & successful \\
\hline
\end{tabular}

\section{Patterns and implications of predator identity}

Bachman's Sparrow nest predator diversity matches the diverse suite of predators recorded for ground-nesting species throughout North America (DeGregorio et al. 2016). Snakes are more common predators of bird nests in the southeastern United States relative to prairie-nesting species further north (Thompson and Ribic 2012, DeGregorio et al. 2016), which may be due to high species diversity and abundance of snakes in the southeast or because warmer temperatures allow for extended activity periods for snakes (Huey 1982). We found that snakes were responsible for more than twice as many depredations of video-monitored Bachman's Sparrow nests than any other predator type. Racers and corn snakes were responsible for a large proportion of depredations in our study (19\% of depredations each) relative to previous songbird studies in the southeast (DeGregorio et al. 2016) whereas gray rat snakes were not prevalent nest predators in our system. The earliest observations of Bachman's Sparrow nest depredations were by snakes, although the species was not reported (Haggerty 1988).

In a review of nest surveillance studies across North America, mesomammals were the dominant predator type, of which $31 \%$ of depredations were by raccoons (DeGregorio et al. 2016). By contrast, we did not document predation by a raccoon. Although we only present data here on Bachman's Sparrow, we also videomonitored Northern Bobwhite nests concurrently at the same sites; raccoons accounted for $23 \%$ of the nest depredations $(N=$ 30 ), indicating raccoons were present and active at our sites. Bachman's Sparrows usually avoid placing nests in areas that have not been burned in the last 12 months (Jones et al. 2013), and raccoons are more likely to forage in areas that were not recently burned (Jones et al. 2004), suggesting a link between fire management and raccoon nest predation.

Our sample of nests is biased toward the nestling stage (55 of 86 nests were found during the nestling stage). Because we used mostly visual cues from provisioning parents to find nests, and snakes use the same cues (Mullin and Cooper 1998, Lillywhite
2014), it is possible that our results are biased toward snakes (Stake et al. 2005). However, of the seven depredations by a black racer, $57 \%$ were during the incubation stage, and of the seven depredations by a corn snake, $28 \%$ were during incubation, meaning the dominance of snakes in our dataset is only partially driven by depredations during the nestling stage.

\section{Nest defense behavior}

Nest defense behavior of Bachman's Sparrow was comparable to other Passerelid sparrows of the tallgrass prairie (Ellison and Ribic 2012). Among grassland-nesting passerines of the Midwest, nest defense appears relatively common (26\%; Pietz and Granfors 2005) although variable by species, predator community, and habitat type. The reaction of one parent in our study against a cottonmouth was similar to the distraction displays that Haggerty (1986) described by a Bachman's Sparrow while defending fledglings against a snake. Nest defense by Bachman's Sparrows appears to be a last-ditch effort to prevent predation, which is attempted only when the predator has encountered the nest. Given the importance of cryptic behavior at the nest to grassland sparrows, and the context in which nest defense generally occurs, it is unsurprising that such behavior by Bachman's Sparrow was rare (exhibited at $16 \%$ of predation events in our sample). Nest defense does not appear to be a key strategy in nest survival for Bachman's Sparrow.

\section{Conservation implications}

Large private properties managed for recreational Northern Bobwhite hunting are common throughout the southeast and create and maintain habitat that supports Bachman's Sparrow populations. Management schemes across these properties are similar, especially throughout the Red Hills region, and almost always include mesomammal trapping and removal (Jackson et al. 2018, Palmer et al. 2019). Thus, we believe our results apply to a considerable portion of Bachman's Sparrow habitat, especially to the approximately 240,000-ha region surrounding our study sites that is mostly old-field pine savanna managed for Northern Bobwhite. However, Bachman's Sparrow nest predator suite may differ on properties that do not trap and remove mesomammals. 
Predatory and competitive interactions within and between predator types in this system are largely unknown but may complicate management actions aimed at reducing nest loss. The reduction of mesomammals for Northern Bobwhite management, which are predators of snakes (Llewellyn and Uhler 1952, Litvaitis 1981, Godbois et al. 2003), could ease predation pressure on snakes, and thus negatively impact nest success of groundnesting birds. Mesomammals were still present and active during our study, as we documented them as the predominate predator at Northern Bobwhite nests at the same sites.

Although habitat loss is the primary factor driving the range-wide decline of Bachman's Sparrow, mitigating nest predation may be desirable when daily nest survival is lower than average or if population growth rate is sensitive to nest success. The daily nest survival rate observed in this study is similar to previous studies and may not be a concern for population persistence at our study sites (Haggerty 1988; 0.919-0.965, Jones et al. 2013; 0.96, Winiarski et al. 2017b;0.916-0.972). Long-term point count data at one of our study sites indicates that the Bachman's Sparrow population there is stable (Tall Timbers, unpublished data), although range-wide and state-wide trends for Bachman's Sparrow in Florida and Georgia are declining (Sauer et al. 2017).

Sound habitat management is the best option for improving demographic resilience of wildlife and the success of conservation efforts. Frequent prescribed fire is particularly important for Bachman's Sparrow because many of its life history traits are closely linked to frequent fire (Dunning et al. 2018) including nest site selection (Jones et al. 2013). Increased time since fire can increase snake predation of Grasshopper Sparrow nests (Ammodramus savannarum; Lyons et al. 2015) because grassland snakes make less-frequent use of recently burned areas (Cavitt 2000). Given the importance of fire for nesting Bachman's Sparrows (Jones et al. 2013), this relationship between snake predation and time since fire may also exist for Bachman's Sparrow. Future studies should explore the link between prescribed fire, nest predation, and snake abundance or activity in southeastern pine savanna.

Responses to this article can be read online at:

http://www.ace-eco.org/issues/responses.php/1409

\section{Acknowledgments:}

Funding was provided by Tall Timbers, University of Florida and small grants from Florida Ornithological Society and Cooper Ornithological Society. Support also came from USDA National Institute of Food and Agriculture, Hatch project \#0215824, KES, $P I$. We thank the technicians who helped find nests and review video: Lizabeth LaBriola, Karis Ritenour, Aaron Yappert, Lindsay Partymiller, Dylan Orlando, and Henry Brown. We thank Jim Cox for his guidance on field techniques and for helpful comments on this manuscript. We thank Joe Noble for technical support with surveillance systems and video file storage and the land management teams at Tall Timbers and Dixie Plantation for their logistical support in the field. Author contributions: KMM and HHJ conceived the study and performed field work. TMT and KES provided funding and aided with study design. KMM and $A M B$ reviewed video and managed the data. KMM analyzed the data. $K M M$ and HHJ wrote the first draft of the manuscript and all authors contributed substantial edits.

\section{LITERATURE CITED}

Andren, H. 1992. Corvid density and nest predation in relation to forest fragmentation: a landscape perspective. Ecology 73 (3):794-804. https://doi.org/10.2307/1940158

Betancourt, A. M., K. M. Malone, and K. E. Sieving. 2017. Two new defense behaviors of the Bachman's Sparrow: a new look at the breeding behavior using video surveillance. Undergraduate Honors Thesis, University of Florida, Gainesville, Florida, USA.

Brennan, L. A., and W. P. Kuvlesky. 2005. North American grassland birds: an unfolding conservation crisis? Journal of Wildlife Management 69(1):1-13. https://doi.org/10.2193/0022-541x (2005)069<0001:nagbau $>2.0$. co;2

Brooks, S. P., and G. O. Roberts. 1998. Convergence assessment techniques for Markov chain Monte Carlo. Statistics and Computing 8(4):319-335.

Cavitt, J. F. 2000. Fire and a tallgrass prairie reptile community: effects on relative abundance and seasonal activity. Journal of Herpetology 34(1):12-20. https://doi.org/10.2307/1565233

Colombelli-Négrel, D., and S. Kleindorfer. 2009. Nest height, nest concealment, and predator type predict nest predation in superb fairy-wrens (Malurus cyaneus). Ecological Research 24 (4):921-928. https://doi.org/10.1007/s11284-008-0569-y

Cox, J. A., and C. D. Jones. 2007. Home range and survival characteristics of male Bachman's Sparrows in an old-growth forest managed with breeding season burns. Journal of Field Ornithology 78(3):263-269. https://doi.org/10.1111/j.1557-9263.2007.00113. $\mathrm{x}$

Cox, J. A., and C. D. Jones. 2009. Influence of prescribed fire on winter abundance of Bachman's Sparrow. Wilson Journal of Ornithology 121(2):359-365. https://doi.org/10.1676/07-138.1

Cox, W. A., M. S. Pruett, T. J. Benson, S. J. Chiavacci, and F. R. Thompson III. 2012. Development of camera technology for monitoring nests. Pages 185-198 in C. A. Ribic, F. R. Thompson III, and P. J. Pietz, editors. Video surveillance of nesting birds. University of California Press, Berkeley, California, USA. https:// doi.org/10.1525/california/9780520273139.003.0015

Curio, E., G. Klump, and K. Regelmann. 1983. An anti-predator response in the Great Tit (Parus major): Is it tuned to predator risk? Oecologia 60(1):83-88. https://doi.org/10.1007/BF00379324

Darrah, A. J., J. B. Cohen, and P. M. Castelli. 2018. A Bayesian multinomial logistic exposure model for estimating probabilities of competing sources of nest failure. Ibis 160(1):23-35. https:// doi.org/10.1111/ibi.12510

DeGregorio, B. A., S. J. Chiavacci, T. J. Benson, J. H. Sperry, and P. J. Weatherhead. 2016. Nest predators of North American birds: continental patterns and implications. Bioscience 66(8):655-665. https://doi.org/10.1093/biosci/biw071

DeGregorio, B. A., P. J. Weatherhead, and J. H. Sperry. 2014. Power lines, roads, and avian nest survival: effects on predator 
identity and predation intensity. Ecology and Evolution 4 (9):1589-1600. https://doi.org/10.1002/ece3.1049

Dijak, W. D., and F. R. Thompson III. 2000. Landscape and edge effects on the distribution of mammalian predators in Missouri. Journal of Wildlife Management 64(1):209-216. https://doi. org $/ 10.2307 / 3802992$

Dunning, J. B., P. Pyle, and M. A. Patten. 2018. Bachman's Sparrow (Peucaea aestivalis). In P. G. Rodewald, editor. The birds of North America online. Cornell Lab of Ornithology, Ithaca, New York, USA. https://doi.org/10.2173/bna.bacspa.03.1

Ellis-Felege, S. N., J. S. Burnam, W. E. Palmer, D. C. Sisson, and J. P. Carroll. 2013. Fight or flight: parental decisions about predators at nests of Northern Bobwhites (Colinus virginianus). Auk 130(4):637-644. https://doi.org/10.1525/auk.2013.12227

Ellison, K. S., and C. A. Ribic. 2012. Nest defense: grassland bird responses to snakes. Pages 149-160 in C. A. Ribic, F. R. Thompson III, and P. J. Pietz, editors. Video surveillance of nesting birds. University of California Press, Berkeley, California, USA. https:// doi.org/10.1525/california/9780520273139.003.0012

Ellison, K. S., C. A. Ribic, D. W. Sample, M. J. Fawcett, and J. D. Dadisman. 2013. Impacts of tree rows on grassland birds and potential nest predators: a removal experiment. PLOS ONE 8(4): e59151. https://doi.org/10.1371/journal.pone.0059151

Godbois, I. A., L. M. Conner, and R. J. Warren. 2003. Bobcat diet on an area managed for northern bobwhite. Proceedings of the Southeastern Association of Fish and Wildlife Agencies 57:222-227.

Haggerty, T. M. 1986. Reproductive ecology of Bachman's Sparrow (Aimophila aestivalis) in central Arkansas. Dissertation. University of Arkansas, Fayetteville, Arkansas, USA.

Haggerty, T. M. 1988. Aspects of the breeding biology and productivity of Bachman's Sparrow in central Arkansas. Wilson Bulletin 100:247-255.

Haggerty, T. M. 1995. Nest-site selection, nest design and nestentrance orientation in Bachman's Sparrow. Southwestern Naturalist 40:62-67.

Hannon, S. J., and S. E. Cotterill. 1998. Nest predation in aspen woodlots in an agricultural area in Alberta: the enemy from within. Auk 115(1):16-25. https://doi.org/10.2307/4089107

Huey, R. B. 1982. Temperature, physiology, and the ecology of reptiles. Pages 25-92 in C. Gans, and F. H. Pough, editors. Biology of the reptilia, Vol. 12. Academic, London, UK.

Jackson, A. L., W. E. Palmer, D. C. Sisson, T. M. Terhune, and J. A. Martin. 2018. Partial meso-mammal predator removal positively affects Northern Bobwhite reproduction. Wildlife Biology 2018(1). https://doi.org/10.2981/wlb.00357

Jones, C. D., J. A. Cox, E. Toriani-Moura, and R. J. Cooper. 2013. Nest-site characteristics of Bachman's Sparrows and their relationship to plant succession following prescribed burns. Wilson Journal of Ornithology 125(2):293-300. https://doi. org/10.1676/12-119.1

Jones, C. D., K. W. Stodola, J. Coombs, M. P. Ward, and R. J. Cooper. 2017. Responses of Bachman's Sparrows and prairie warblers to fragmentation. Journal of Wildlife Management 81 (2):347-355. https://doi.org/10.1002/jwmg.21195

Jones, D. D., L. M. Conner, T. H. Storey, and R. J. Warren. 2004. Prescribed fire and raccoon use of longleaf pine forests: implications for managing nest predation? Wildlife Society Bulletin 32(4):1255-1259.

Kleindorfer, S., B. Fessl, and H. Hoi. 2005. Avian nest defence behaviour: assessment in relation to predator distance and type, and nest height. Animal Behaviour 69(2):307-313. https://doi. org/10.1016/j.anbehav.2004.06.003

Kéry, M. 2010. Introduction to WinBUGS for ecologists: a Bayesian approach to regression, ANOVA, mixed models and related analyses. Academic, Burlington, Massachusetts, USA.

Le Cam, L. 1990. Maximum likelihood: an introduction. International Statistical Review/Revue Internationale de Statistique 58(2):153-171. https://doi.org/10.2307/1403464

Lillywhite, H. B. 2014. How snakes work: structure, function, and behavior of the world's snakes. Oxford University Press, New York, New York, USA.

Litvaitis, J. A. 1981. A comparison of coyote and bobcat food habits in the Wichita Mountains, Oklahoma. Proceedings of the Oklahoma Academy of Science 61:81-82.

Llewellyn, L. M., and F. M. Uhler. 1952. The foods of fur animals of the Patuxent Research Refuge, Maryland. American Midland Naturalist 48(1):193-203. https://doi.org/10.2307/2422142

Lyons, T. P., J. R. Miller, D. M. Debinski, and D. M. Engle. 2015. Predator identity influences the effect of habitat management on nest predation. Ecological Applications 25(6):1596-1605. https:// doi.org/10.1890/14-1641.1

Mullin, S. J., and R. J. Cooper. 1998. The foraging ecology of the gray rat snake (Elaphe obsoleta spiloides)-visual stimuli facilitate location of arboreal prey. American Midland Naturalist 140 (2):397-401. https://doi.org/10.1674/0003-0031(1998)140[0397: TFEOTG]2.0.CO;2

North American Bird Conservation Initiative (NABCI). 2017. The state of North America's birds 2016. Environment and Climate Change Canada, Ottawa, Ontario, Canada. [online] URL: http:// www.stateofthebirds.org//

Nour, N., E. Matthysen, and A. A. Dhondt. 1993. Artificial nest predation and habitat fragmentation: different trends in bird and mammal predators. Ecography 16(2):111-116. https://doi. org/10.1111/j.1600-0587.1993.tb00063.x

Palmer, W. E., J. P. Carroll, D. C. Sisson, S. D. Wellendorf, T. M. Terhune II, S. N. Ellis-Felege, and J. A. Martin. 2019. Reduction in meso-mammal nest predators improves Northern Bobwhite demographics. Journal of Wildlife Management 83(3):646-656. https://doi.org/10.1002/jwmg.21627

Pietz, P. J., and D. A. Granfors. 2005. Parental nest defense on videotape: more reality than "myth." Auk 122(2):701-705. https:// doi.org/10.1642/0004-8038(2005)122[0701:PNDOVM]2.0.CO;2

Plummer, M. 2013. Just another Gibbs sampler (jags) software, version-3.4.0. 
R Development Core Team. 2016. R: a language and environment for statistical computing. R Foundation for Statistical Computing, Vienna, Austria.

Renfrew, R. B., and C. A. Ribic. 2003. Grassland passerine nest predators near pasture edges identified on videotape. Auk 120 (2):371-383. https://doi.org/10.2307/4090189

Royle, J. A., and R. M. Dorazio. 2008. Hierarchical modeling and inference in ecology: the analysis of data from populations, metapopulations and communities. Academic, San Diego, California, USA.

Sanders, M. D., and R. F. Maloney. 2002. Causes of mortality at nests of ground-nesting birds in the Upper Waitaki Basin, South Island, New Zealand: a 5-year video study. Biological Conservation 106(2):225-236. https://doi.org/10.1016/s0006-3207 (01)00248-8

Sauer, J. R., D. K. Niven, J. E. Hines, D. J. Ziolkowski Jr., K. L. Pardieck, J. E. Fallon, and W. A. Link. 2017. The North American breeding bird survey, results and analysis 1966-2015. Version 2.07.2017, U.S. Geological Survey Patuxent Wildlife Research Center, Laurel, Maryland, USA.

Schmidt, K. A. 1999. Foraging theory as a conceptual framework for studying nest predation. Oikos 85(1):151-160. https://doi. org/10.2307/3546801

Schmidt, K. A., and C. J. Whelan. 2005. Quantifying male Wood Thrush nest-attendance and its relationship to nest success. Condor 107(1):138-144. https://doi.org/10.1650/7582

Sovada, M. A., A. B. Sargeant, and J. W. Grier. 1995. Differential effects of coyotes and red foxes on duck nest success. Journal of Wildlife Management 59(1):1-9. https://doi.org/10.2307/3809108

Stake, M. M., F. R. Thompson, J. Faaborg, and D. E Burhans. 2005. Patterns of snake predation at songbird nests in Missouri and Texas. Journal of Herpetology 39(2):215-222. https://doi. org/10.1670/150-04A

Taillie, P. J., M. N. Peterson, and C. E. Moorman. 2015. The relative importance of multiscale factors in the distribution of Bachman's Sparrow and the implications for ecosystem conservation. Condor 117(2):137-146. https://doi.org/10.1650/ CONDOR-14-137.1

Thompson III, F. R., and C. A. Ribic. 2012. Conservation implications when the nest predators are known. Pages 23-34 in C. A. Ribic, F. R. Thompson III, and P. J. Pietz, editors. Video surveillance of nesting birds. University of California Press, Berkeley, California, USA. https://doi.org/10.1525/ california/9780520273139.003.0002

Tucker, J. W., W. D Robinson, and J. B. Grand. 2004. Influence of fire on Bachman's Sparrow, an endemic North American songbird. Journal of Wildlife Management 68(4):1114-1123. https://doi.org/10.2193/0022-541X(2004)068[1114:IOFOBS]2.0.CO;2

Vickery, P. D., M. L. Hunter, Jr, and J. V. Wells. 1992. Evidence of incidental nest predation and its effects on nests of threatened grassland birds. Oikos 63(2):281-288. https://doi.org/10.2307/3545389

Winiarski, J. M., A. C. Fish, C. E. Moorman, J. P. Carpenter, C. S. Deperno, and J. M. Schillaci. 2017b. Nest-site selection and nest survival of Bachman's Sparrows in two longleaf pine communities. Condor 119(3):361-374. https://doi.org/10.1650/ condor-16-220.1

Winiarski, J. M., C. E. Moorman, J. P. Carpenter, and G. R. Hess. 2017a. Reproductive consequences of habitat fragmentation for a declining resident bird of the longleaf pine ecosystem. Ecosphere 8(7):e01898. https://doi.org/10.1002/ecs2.1898

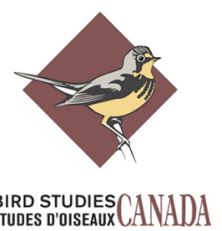

